\title{
Surface Structure Formation in Direct Chill (DC) Casting of Al Alloys
}

\author{
NAZLIN BAYAT ${ }^{1}$ and TORBJÖRN CARLBERG ${ }^{1,2}$ \\ 1.-Department of Natural Science, Mid Sweden University, Holmgatan 10, 85170 Sundsvall, \\ Sweden. 2.-e-mail: torbjorn.carlberg@miun.se
}

The aim of this study is to increase the understanding of the surface zone formation during direct chill (DC) casting of aluminum billets produced by the air slip technology. The depth of the shell zone, with compositions deviating from the bulk, is of large importance for the subsequent extrusion productivity and quality of final products. The surface microstructures of 6060 and 6005 aluminum alloys in three different surface appearances-defect free, wavy surface, and spot defects-were studied. The surface microstructures and outer appearance, segregation depth, and phase formation were investigated for the mentioned cases. The results were discussed and explained based on the exudation of liquid metal through the mushy zone and the fact that the exudated liquid is contained within a surface oxide skin. Outward solidification in the surface layer was quantitatively analyzed, and the oxide skin movements explained meniscus line formation. Phases forming at different positions in the segregation zone were analyzed and coupled to a cellular solidification in the exudated layer.

\section{INTRODUCTION}

The direct chill (DC) casting technique to produce semifinished aluminum castings, in other words billets for extrusion and ingots for rolling, was developed in the $1930 \mathrm{~s}^{1}$ The principle, which is still valid, is a two-stage cooling with a primary cooling at a mold surface followed by water spraying directly on the surface. ${ }^{2-4}$ Improvements on this technique have mainly focused on changes to the primary cooling, where a water-cooled metal mold has been replaced by different techniques to minimize cooling at this stage. The drive for development comes from the profile extrusion industry, which can increase the productivity and quality of extruded profiles by improving the billet surface appearance and structure. ${ }^{5,6}$ Hot top casting supported by airflow against the casting surface during the primary cooling is currently the standard procedure to achieve acceptable billet surfaces. The goal is to minimize the depth of the surface segregation zone, which is the governing factor for the appearance of different phases in the surface region. Billet surface quality is evaluated by quantifying surface appearance, segregation zone thickness, and occurrence of large $\mathrm{Mg}_{2} \mathrm{Si}$ and $\beta$-particles near the surface. The surface segregation is a macrosegregation defined as a heterogeneous distribution of alloying elements with long-range compositional differences between the outside and inside of this area. $^{7-9}$

Surface segregation in DC cast billets has been discussed in the literature (for example, References. 4 and 10-13). Specifically, the formation of the so-called lapping surface or Bergmann zones ${ }^{4}$ with a wavy or banded surface appearance has been the subject of different theories. ${ }^{6,10}$ It is, however, important to distinguish between older types of casting techniques where primary cooling occurs through direct contact with a cooled metal mold and the modern air-slip technique. Although this technique gives a much thinner segregation zone, the concentration of alloy elements at the surface is about five to six times higher than the bulk concentration at smooth surfaces without lapping. ${ }^{13}$ Therefore, the formation of the segregation zone, also at smooth defect-free surfaces, must be discussed.

The industrial development of the casting technique to improve surface appearance has not always been based on an understanding of how the surface zone is formed. Structural observations, 

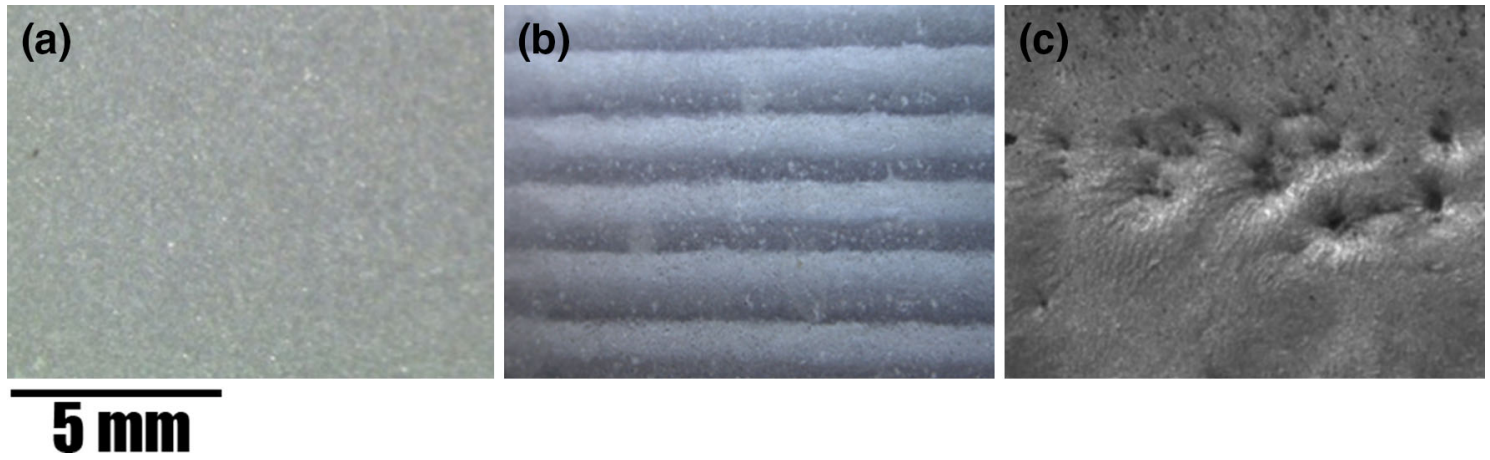

Fig. 1. The stereo light microscope images: (a) smooth surface, (b) wavy surface, and (c) spot defects.

Table I. Chemical compositions of 6060 and $6005 \mathrm{Al}$ alloys

\begin{tabular}{|c|c|c|c|c|c|c|c|c|}
\hline Alloy & $\mathbf{S i}$ & $\mathbf{F e}$ & $\mathbf{C u}$ & Mn & Mg & $\mathbf{C r}$ & Zn & $\mathbf{T i}$ \\
\hline 6005 & 0.65 & 0.22 & 0.08 & 0.15 & 0.54 & 0.001 & 0.15 & 0.037 \\
\hline 6060 & 0.41 & 0.19 & 0.002 & 0.02 & 0.47 & 0.0006 & 0.004 & 0.016 \\
\hline
\end{tabular}

macrosegregation models, and composition mapping have not been tied together in a comprehensive way to describe the surface zone formation. This article is focused on understanding the formation of the surface segregation at the quantitative level for both smooth defect-free surfaces and surfaces with lapping (Fig. 1a and b, respectively). This is done as a comparison between some of the most frequently produced alloys applied in the extrusion industry.

Different types of spot defects (Fig. 1c) also occur during air-slip casting, which are generally regarded as the results of oxide fragments releasing from the top plate. The formation of such spots is also part of the study, as the microscopic observations of the spots give information of general importance for the surface formation.

\section{EXPERIMENTAL PROCEDURE}

Microstructures and surface segregation of 6060 and $6005 \mathrm{Al}$ alloy with a smooth, wavy appearance and spot defects were investigated. The compositions of mentioned alloys are given in Table I.

The samples were cut transverse to the surface and along the growth direction, and then they were mounted and polished. The cutting plane of spot defects ran through the center of the spot. The wavy defect sample was cut in the vertical direction to the waves, i.e., along the billet.

Surface segregation of the mentioned samples was studied by a light optic microscope (LOM). A scanning electron microscope (SEM) was used to observe the directly unprepared surface structures. The microstructures and formed phases of samples from six billets were compared, and different segregation thicknesses, phases, and microstructures were analyzed. Different phases were analyzed by energy-dispersive x-ray spectroscopy (EDX).

\section{RESULTS}

In Fig. 2a and b, the surface segregations of the defect-free billets for both 6060 and 6005 are illustrated in cuts along the interfaces. In these smooth (defect free) surfaces, the segregation thickness is uniform and it is about 50-70 $\mu \mathrm{m}$ and 120-150 $\mu \mathrm{m}$ for 6060 and 6005 alloys, respectively. The surface segregation depths around defects are not uniform, which can be seen at both wavy surfaces and spot defects (Fig. 2c through f). The segregation zone depths vary strongly in the wavy defect samples (Fig. 2c and d), which are 20-100 $\mu \mathrm{m}$ and $30-200 \mu \mathrm{m}$ in 6060 and 6005 alloys, respectively. In Figs. $2 \mathrm{e}$ and $\mathrm{f}$, it can be seen that the segregation at some distances from a spot is thicker than at the center of the spot.

In the wavy samples for both alloys, so-called meniscus lines can be observed. These lines seem to start just after the bottom of a valley (at the arrow in Fig. 2c) and bend inward when the surface starts to perturb. By comparing Fig. 2c and d, the meniscus line promotion inward is deeper in the 6005 alloy, even though the valleys on the surface are not as deep as in the 6060 alloy sample. It is also obvious that at the starting point of a meniscus line, in the valleys, the exudation of high-alloy elements is negligible or does not exist at all, which can be seen just before the arrow in Fig. 2c.

Figure $3 \mathrm{a}$ and $\mathrm{b}$ shows smooth defect-free surfaces from 6060 and 6005 billets, respectively, viewed by SEM directly on unprepared samples. Light phases in broom-like (fan-shaped) ${ }^{14}$ appearance dominate the structure, and the fan shapes are 
(a)

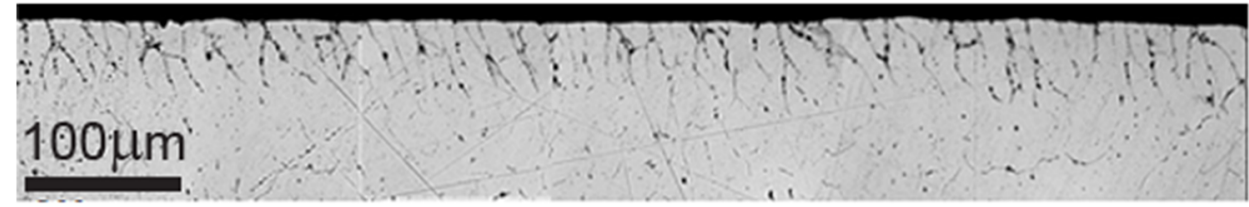

(b)
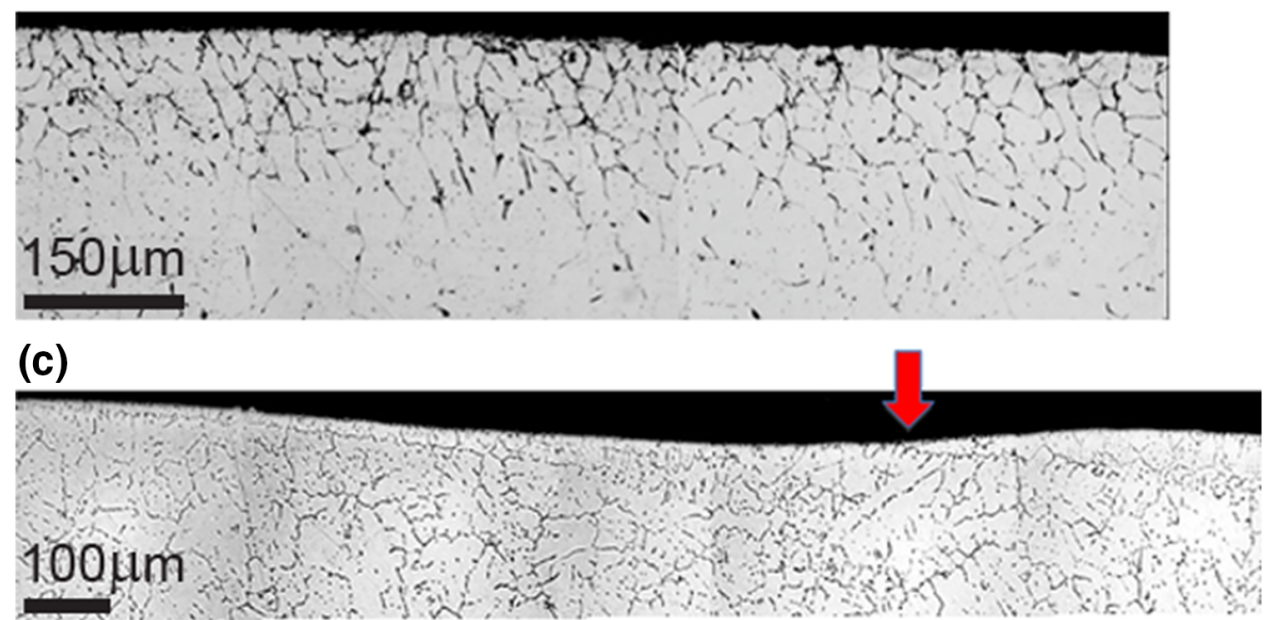

(d)

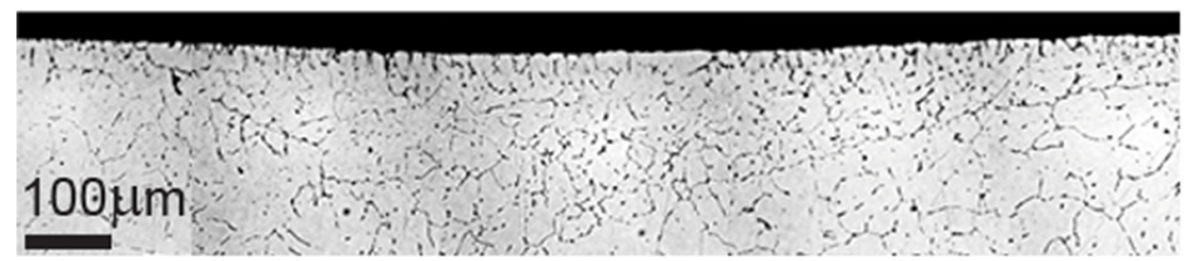

(e)

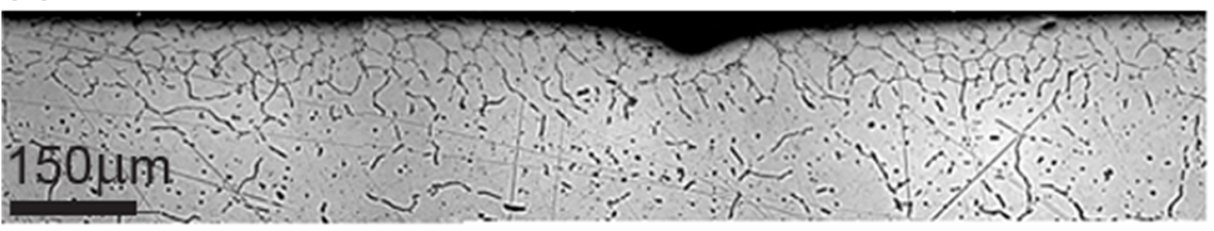

(f)

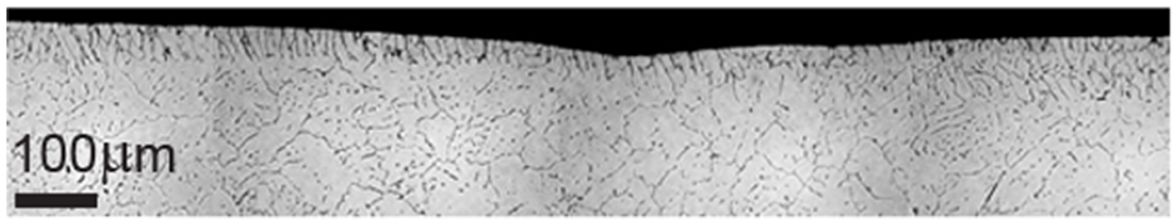

Fig. 2. Microstructures in cross sections along the growth direction from: (a) smooth surface of 6060; (b) smooth surface of 6005; (c) wavy surface in 6060, growth direction to the right; (d) wavy surface in 6005, growth direction to the left; (e) spot defect in 6060; and (f) spot defect in $6005 \mathrm{Al}$ alloys.

more obvious in the 6060 alloy. In the background of both alloys, but more clearly seen in the 6005, a cellular structure is visible, where cells or dendrite tips have grown toward the surface. In 6060 (Fig. 3a), the cells are elongated and the light phases are sometimes aligned to the intercellular regions.
In Fig. 3c, from the 6060 alloy, and Fig. 3d, from the 6005 alloy, a more detailed view of the surface phases is shown together with the EDX spectra. Figure 3c shows the light plate-like phase, and Fig. 3d shows phases filling out the intercellular grooves. The Fe:Si ratios, recalculated to at.\%, are for the plate-like phases about 1:1 (Fig. 3c), and for 

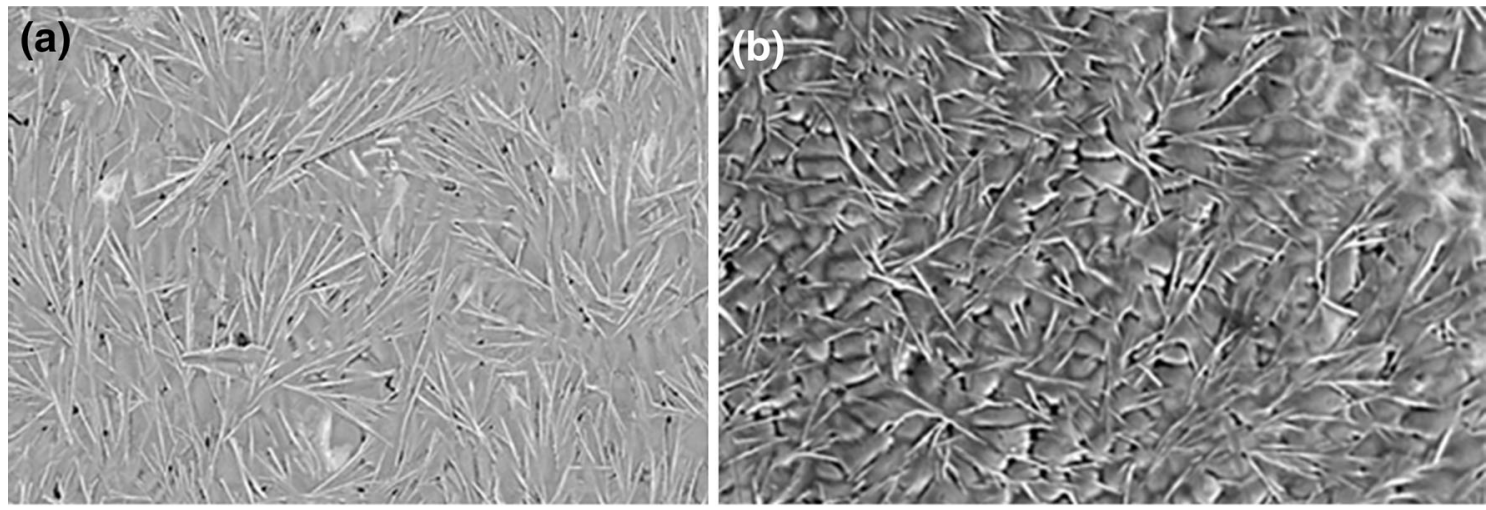

$2 \overline{0} \bar{m}$

$2 \overline{0} \mathrm{~m}$

(c)

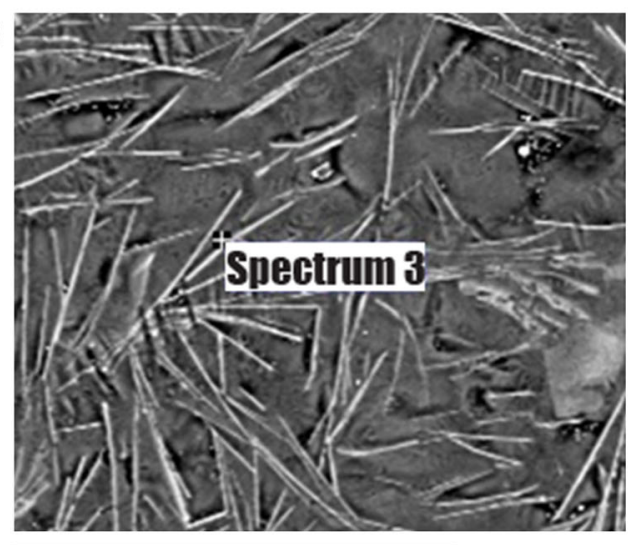

$100 \mu \mathrm{m}$

(d)

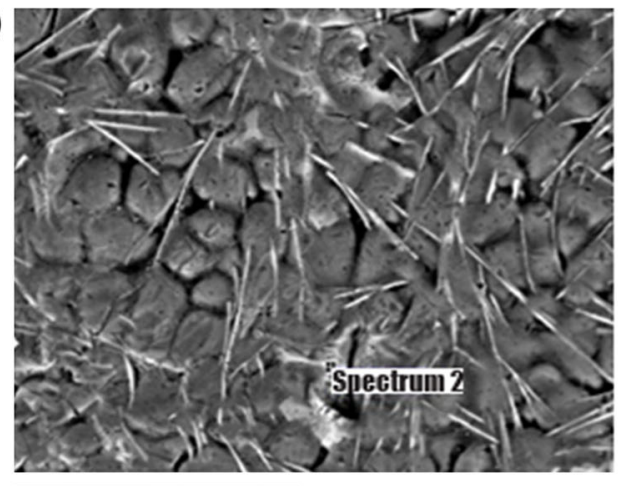

$80 \mu \mathrm{m}$
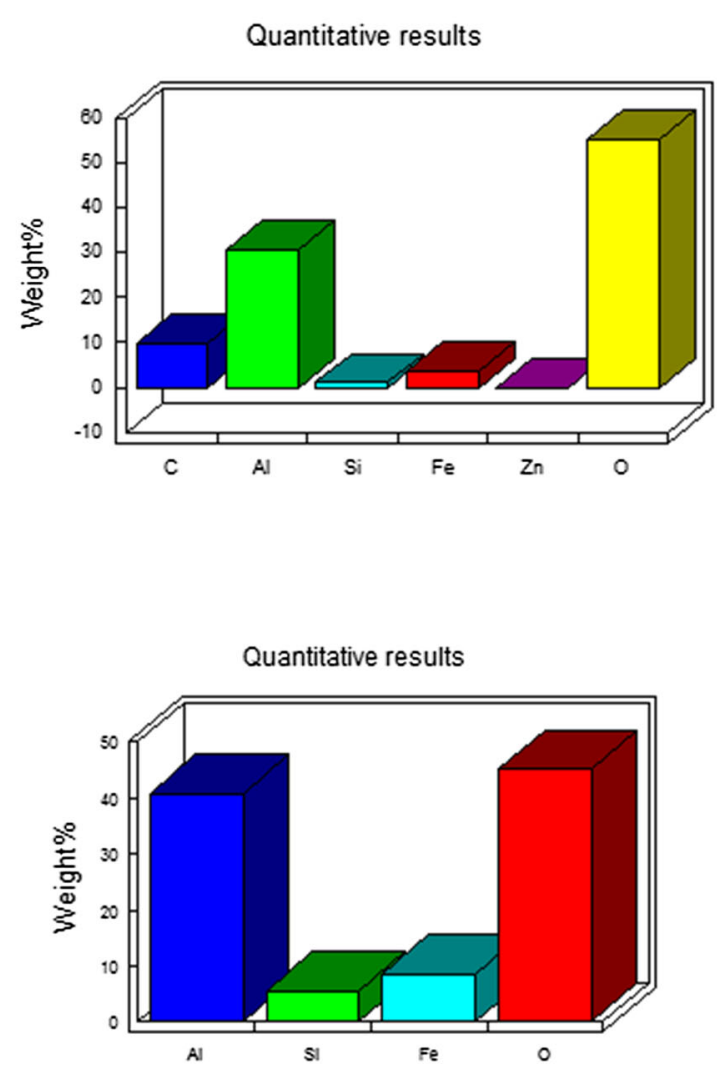

Fig. 3. SEM pictures of surface structures of smooth surfaces of (a) a 6060 alloy, (b) a 6005 alloy, (c) phase on 6060 surface with corresponding EDX spectrum, and (d) phase on 6005 surface with corresponding EDX spectrum.

the morphology filling out the intercellular spacing about 0.8:1 (Fig. 3d). As is seen in Fig. 3a and b, the plate-like phase is dominating at smooth surfaces for both alloys.

In the billets with a banded or wavy surface, the appearances, viewed by an SEM, are shown in Fig. 4. Different phases dominate at different positions along the waves, and phases with a dendritic shape are rather common (Fig. 4a and b). In higher magnification and with an EDX spectrum (Fig. 4d), it is clear that the Fe:Si ratio is about 2:1 (recalculated to at.\%). In Fig. 4e, where the secondary phase is filling out the cell boundaries, the $\mathrm{Fe}: \mathrm{Si}$ ratio is about $1: 1$, which is similar to what was found in Fig. $3 \mathrm{~d}$ for a phase of the same morphology.

In Fig. 5, structures around spot defects are shown, and in these areas it can be seen that the amount of plate-like particles is decreased. The EDX spectra show that $\mathrm{F}, \mathrm{Na}, \mathrm{Ca}$, and $\mathrm{C}$ atoms can be seen around the defects in white particles 


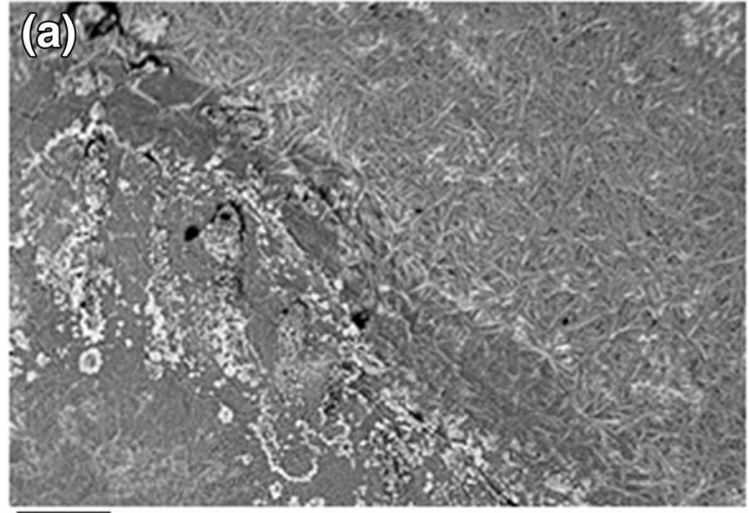

$\overline{200 \mu \mathrm{m}}$

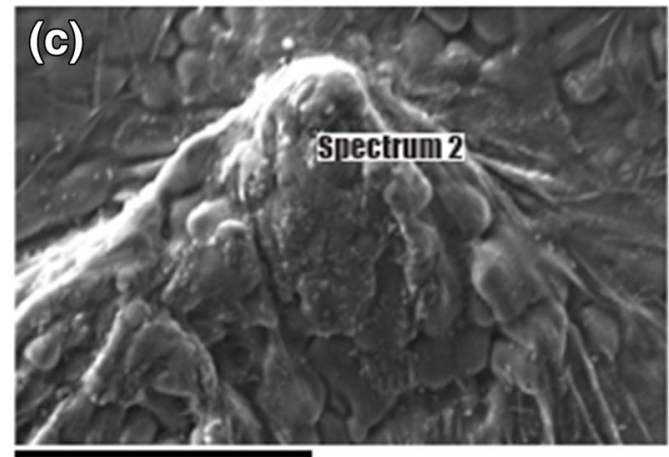

$90 \mu \mathrm{m}$
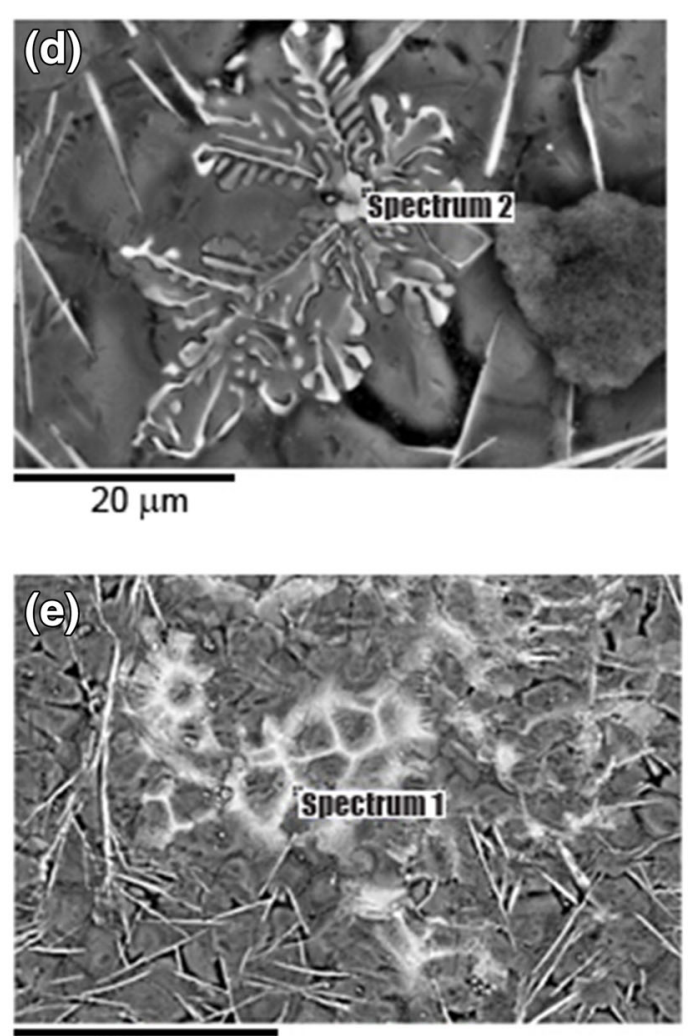

$$
100 \mu \mathrm{m}
$$

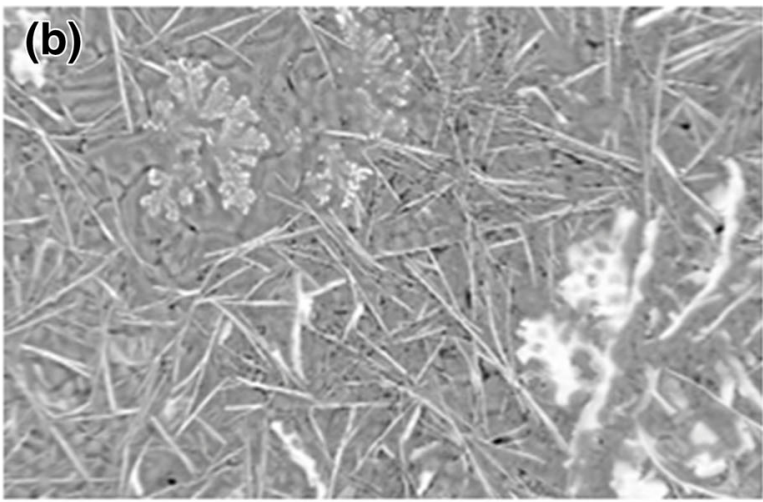

$100 \mu \mathrm{m}$
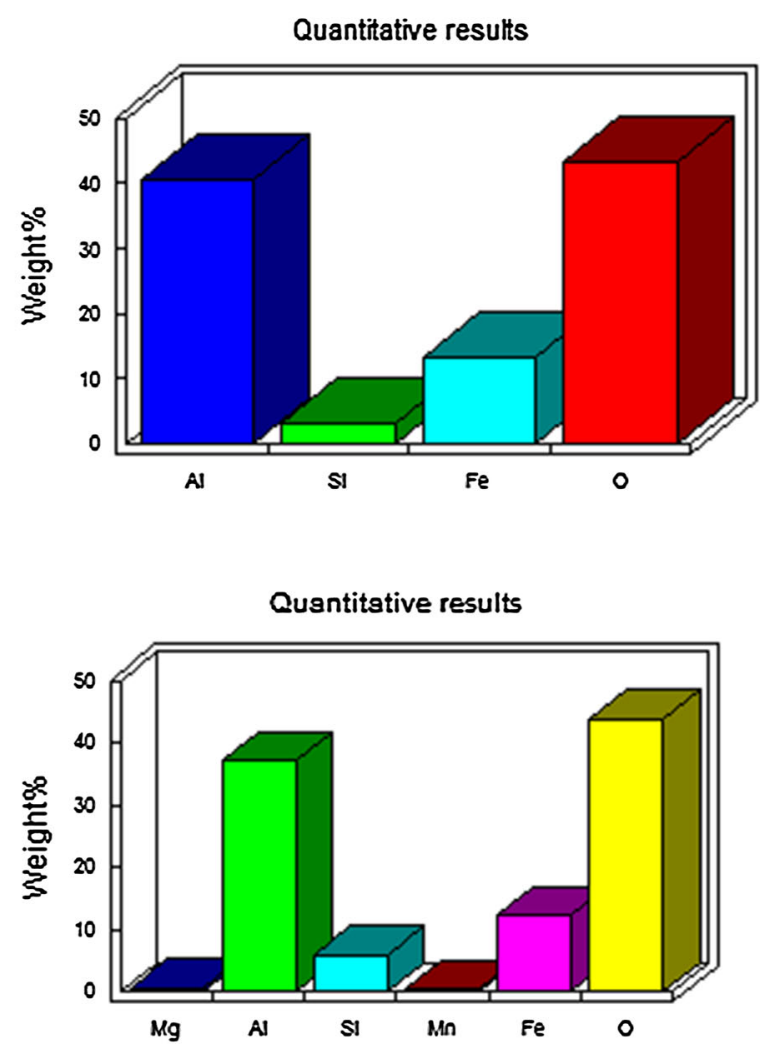

Fig. 4. SEM pictures of surface structures of wavy surfaces of (a) a 6060 alloy, (b) a 6005 alloy, (c) protruding tip in wave on 6060 surface, (d) phase on 6060 surface with corresponding EDX spectrum, and (e) phase on 6005 surface with corresponding EDX spectrum. 

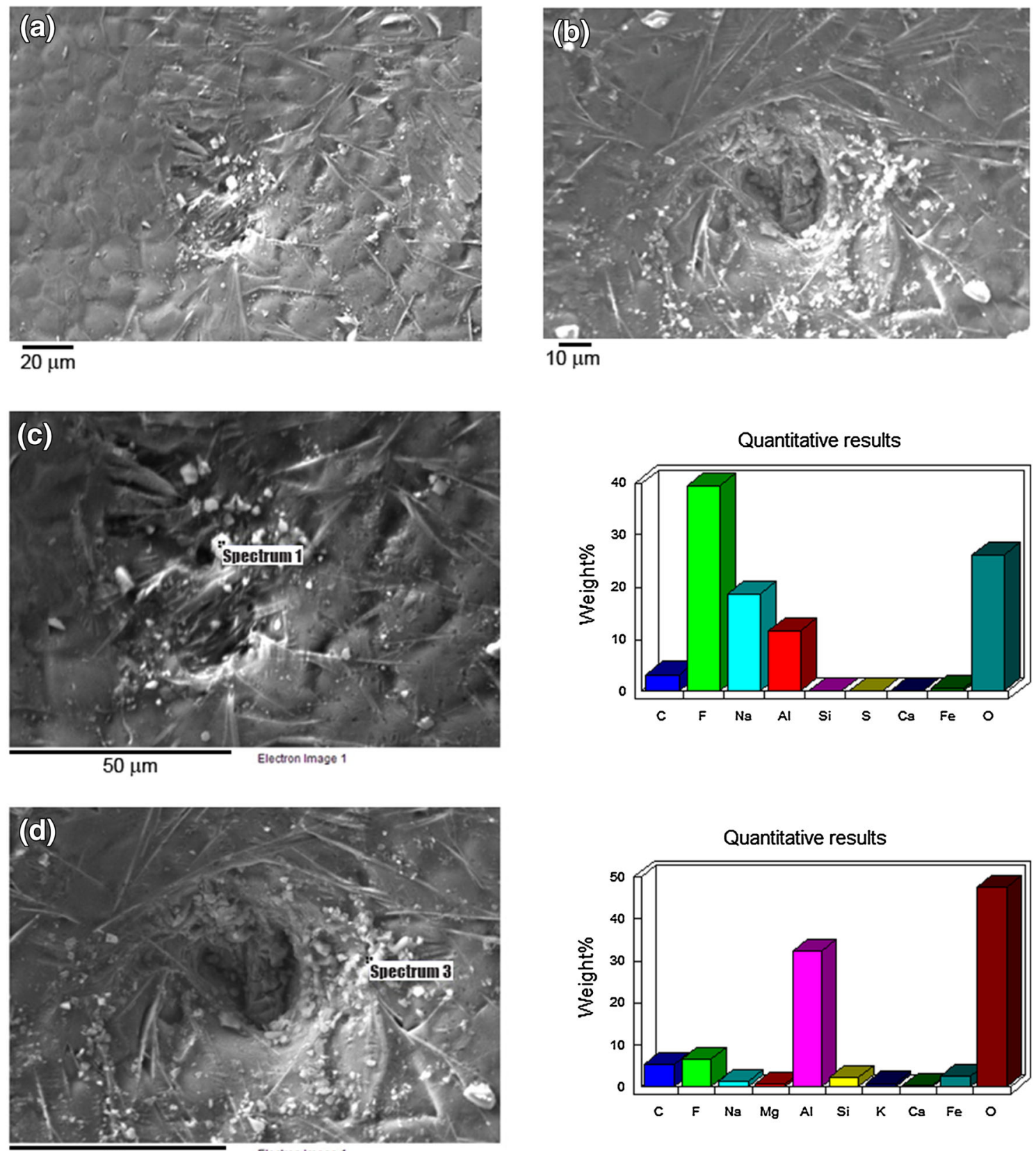

Fig. 5. SEM pictures of surface structures of: (a) spot defect on 6060 and (b) spot defect on 6005, (c) spot on 6060 with corresponding EDX spectrum, and (d) spot on 6005 with corresponding EDX spectrum.

surrounding the spots. Analyses of a number of defects show the same results, and these elements were not found on any other analyzed places in the structures.

\section{DISCUSSION}

\section{Defect-Free Samples}

During $\mathrm{Al}$ casting when the melt is exposed to the air, a layer of oxide forms along the whole surface. ${ }^{15}$ Around spot defects, as shown in Fig. 1c, it is clear that the oxide has wrinkled around the spots, and this clearly illustrates the strength and toughness of the oxide skin. It has also been concluded that it is necessary to have oxide for the air-slip technique to work properly. ${ }^{5,15}$ It is clear from such observations that a liquid layer, formed by exudation from the mushy zone, exists between the solid and the oxide layers. This layer is the last to solidify; that is, an outward or inverse solidification prevails in the outermost part of the billet. This was already observed by McGubbin, ${ }^{10}$ although at that time no 
air-slip technique was used. The same thing was also pointed out for air-slip DC casting by Benum et al. ${ }^{11}$ However, in both those papers, the focus was on segregation at wavy surfaces, as illustrated here in Fig. 1c, and the consequences of the outward solidification were not penetrated. A totally consistent understanding of the surface zone formation, both for smooth and wavy surfaces, has therefore not been published previously. The consequences of the inverse solidification in the surface zone will be analyzed in the following and coupled to recent quantitative data of surface segregation. ${ }^{6,13}$

At smooth surfaces, the segregation zone has a relatively constant thickness (Fig. $2 a$ and b), indicating that this type of surface is obtained when the pressure fluctuations in the melt, and thus the meniscus movements, are minimized. At such conditions, the melt, exudated from the mushy zone to the layer between the oxide and the coherent solid, is relatively constant in time. The thickness of the layer will depend on the metal head pressure, which normally is larger for larger diameters. ${ }^{11,16,17}$ The layer thickness depends even more so on the type of alloy allowing for an increased segregation layer for larger solidification intervals, as shown by modeling in Ref. ${ }^{6}$ and as is seen if Fig. $2 a$ and $b$ are compared.

The typical structure of the outer part of the segregation zone is directed solidification, sometimes at a slightly tilted angle, toward the surface, in Fig. 2a and b. Looking at the structure directly on the outer surface (Fig. 3, specifically Fig. $3 b$ and d), a cellular growth front is revealed. This shows that the outer part of the segregation layer is solidifying outward with a cellular interface. It is, however, not clear if the visible segregation zone in transverse cuts is the same as the total thickness of the exudation layer. In Ref. ${ }^{13}$, the concentration profiles in the surface zone were measured and it was generally observed that the concentration started to increase at about $400 \mu \mathrm{m}$, while the cellular structure started closer to the surface. It is not likely, for the studied alloys, that the exudation layer is as large as $400 \mu \mathrm{m}$, as the air gap formed due to solidification shrinkage will be smaller. ${ }^{6,18}$ Under certain conditions, for example higher alloyed billets and higher metal pressure, the whole air gap can be filled, but in the cases discussed in this article, with smooth surfaces, this is not the case and the liquid layer is thinner. It is instead likely that the point where the cellular growth starts is close to the thickness of the exudated layer. In the following discussion, some theoretical estimations will be done to further understand the solidification in the actual zone. During the outward solidification, segregation occurring at the front should follow a microsegregation pattern. If measured concentration profiles are studied, ${ }^{6,13}$ then a strongly increasing concentration toward the surface indicates a segregation following a simple Scheil plot. However, it is not possible to fit a Scheil curve directly to a surface
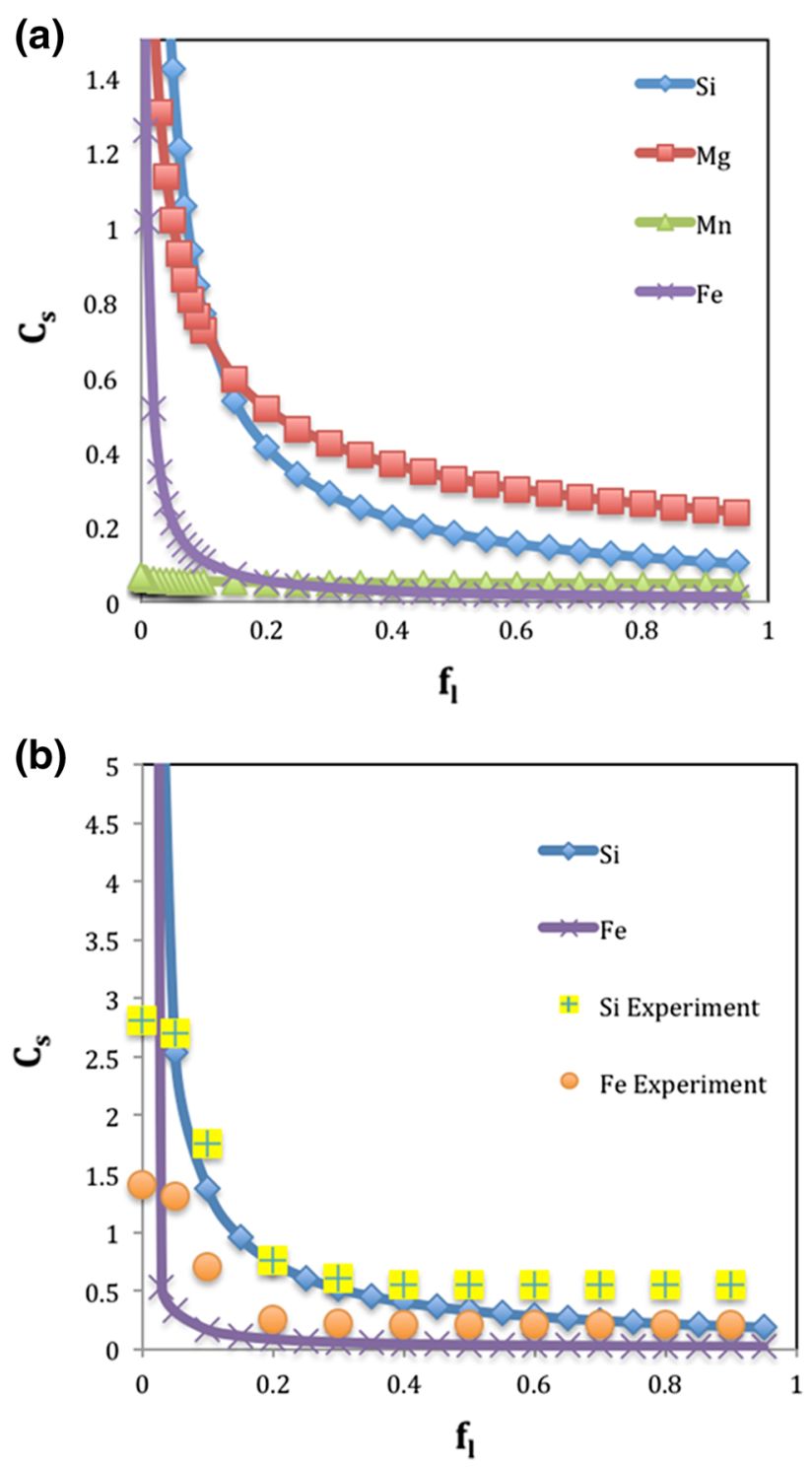

Fig. 6. (a) Scheil equation calculation for 6060 and (b) Scheil equation calculation and experimental results for 6005 alloy.

segregation profile as the profile is a result of first microsegregation between dendrite arms and grains at the same time as liquid is pressed out (the exudated layer), and subsequently that layer solidifies in a directional cellular mode. In Fig. 6, the unmodified Scheil equation has been used to plot possible surface profiles, and in Fig. $6 \mathrm{~b}$, data have been added from an experimental profile of 6005 alloy. ${ }^{13}$ To reasonably fit the data, it must be assumed that the solidification of the exudated layer, $200 \mu \mathrm{m}$ thick in the actual measured profile,$^{13}$ starts when the solid fraction reaches $85 \%$. By doing this, a relatively good fit is obtained, but the surface contents are lower than the calculated. The calculation assumes a planar front and that all solute is rejected outward, but the solidification is cellular and thus the segregation should not be as strong as the theoretical prediction, which explains the difference. 
It can be concluded that the strong accumulation of alloying elements to the surface can be described by segregation during outwards solidification.

From Fig. 2, it seems that a planar interface is broken down and becomes cellular at a certain stage during outward growth, which can be treated by the theory for constitutional super cooling: ${ }^{19}$

$$
\frac{G}{R} \geq \frac{-m_{1} C_{0}(1-K)}{K D_{\mathrm{l}}}, \quad \text { Planar interface. }
$$

From this, the prevailing temperature gradient $(G)$ at interface breakdown can be estimated. The growth rate can be estimated to $0.01(\mathrm{~mm} / \mathrm{s})$ by assuming a layer thickness of $100 \mu \mathrm{m}$, which is solidified in $10 \mathrm{~s}$, in other words about the time it takes for the surface to travel $20 \mathrm{~mm}$. The data used for the liquidus slopes $m$, distribution coefficients $k$, and diffusion coefficients $D$ are shown in Table II. The liquid concentrations $C_{0}$ can be obtained from Fig. 6 as the average concentrations in the segregation zone, that is, in the outer $15 \%$ of the profiles.

From Table II, it can be seen that silicon and iron (in 6005 alloys) first cause the cellular growth at a gradient of about $30^{\circ} \mathrm{C} / \mathrm{cm}$, which corresponds to a temperature difference over the $100-\mu$ m-thick exudated layer of $0.3^{\circ} \mathrm{C}$. This difference, being the result of a balance of the heat flux by radiation from the surface and conduction from the solidification front, is small but obviously enough for the heat to flow from the surface and toward the solidification front. A more accurate estimation would be to calculate a quaternary phase diagram and evaluate a pseudobinary distribution coefficient. However, as a first approximation, the above estimation gives a reasonable value, and the table also shows how the different alloy elements contribute to the growth restriction at the front. The higher alloyed 6005 needs a higher gradient to be stable, which also results in deeper cell boundaries and more developed cell structure, while 6060 shows a more elongated cell structure, which is an earlier stage of cell development (Fig. 3).
The formation of the surface zone during casting of a billet with a smooth surface can be summarized as follows and illustrated by the schematic drawing in Fig. 7, where the isotherms are drawn by dash lines and the liquidus line is green. The solidus isotherm, full line, is bent downward at the surface, and thus forming a peak, apparently growing upward, ${ }^{10}$ and with coherent equiaxed crystals growing close to the solidus. At the very surface and contained by the oxide skin, a liquid layer is constantly being formed as highly concentrated solute is pressed into this layer out of the interdendritic area of the coherent zone. The exudated layer, somewhat warmer than the semisolid shell, which is efficiently cooled from below, creates the bent isotherm, which has not been discussed in previous studies, ${ }^{3-6,11,18,21-25}$ in which anticipated isotherms and thus heat flow directions contradict the observed growth direction.

Due to a smaller solid fraction of 6005 in comparison with the 6060 alloys at the same temperature, increased permeability of the mushy zone will lead to larger exudation ${ }^{6}$ and, thus, to a thicker segregation zone (Fig. $2 \mathrm{a}$ and b). The layer will not immediately solidify, as the melting point is lowered due to the high solute content and the heat loss on the surface is only due to conduction to the air gap ${ }^{26}$ and radiation below the contact point of the graphite ring. At a certain stage, the heat flow through the coherent crystals will be larger than the heat loss through the gap together with the latent heat, and outward growth will start.

The analysis of the constitutional supercooling, as previously mentioned, indicates a temperature difference of $0.3^{\circ} \mathrm{C}$ over the liquid layer at the start of outwards growth. The outward solidification is of a cellular type, and a large part of the solute is pushed toward the oxide skin. During the final solidification on the very surface, the solute concentration is so high that a plate-like phase grows laterally, that is nearly two dimensionally, as primary crystals (Fig. 3). The fan-like pattern, which is partly disconnected from the cellular boundaries, shows that this phase is growing as a primary precipitation in

Table II. Temperature gradient calculations for 6060 and 6005 alloys $\left(m_{1}\right.$ : liquidus slope, $C_{\mathrm{o}}$ : average composition of alloys in segregated area, $K$ : distribution coefficient, and $R$ : solidification rate $)^{20}$

\begin{tabular}{|c|c|c|c|c|c|c|}
\hline Element & $m_{1}$ & $C_{\mathrm{o}}$ & $\boldsymbol{K}$ & $D_{1}\left(\mathrm{~m}^{2} / \mathrm{s}\right)$ & $\boldsymbol{R}(\mathbf{m} / \mathbf{s})$ & $G\left({ }^{\circ} \mathrm{C} / \mathrm{cm}\right)$ \\
\hline \multicolumn{7}{|l|}{6060} \\
\hline $\mathrm{Si}$ & 6.6 & 0.0095 & 0.1 & $2.8 \times 10^{-9}$ & $1 \times 10^{-5}$ & 18.1 \\
\hline $\mathrm{Mg}$ & 6 & 0.0060 & 0.5 & $9.7 \times 10^{-9}$ & $1 \times 10^{-5}$ & 0.4 \\
\hline $\mathrm{Mn}$ & 0.9 & 0.0043 & 0.9 & $3.5 \times 10^{-9}$ & $1 \times 10^{-5}$ & 0.01 \\
\hline $\mathrm{Fe}$ & 8 & 0.0007 & 0.029 & $2.5 \times 10^{-9}$ & $1 \times 10^{-5}$ & 7.3 \\
\hline \multicolumn{7}{|l|}{6005} \\
\hline $\mathrm{Si}$ & 6.6 & 0.0160 & 0.1 & $2.8 \times 10^{-9}$ & $1 \times 10^{-5}$ & 30.5 \\
\hline $\mathrm{Mg}$ & 6 & 0.010 & 0.5 & $9.7 \times 10^{-9}$ & $1 \times 10^{-5}$ & 0.6 \\
\hline $\mathrm{Mn}$ & 0.9 & 0.0085 & 0.9 & $3.5 \times 10^{-9}$ & $1 \times 10^{-5}$ & 0.01 \\
\hline $\mathrm{Fe}$ & 8 & 0.0028 & 0.029 & $2.5 \times 10^{-9}$ & $1 \times 10^{-5}$ & 29.3 \\
\hline
\end{tabular}


the surface layer. The EDX analysis, showing a Fe:Si ratio of $1: 1$, and the plate-like shape indicates that this phase is $\beta$-phase of the type $\left(\mathrm{Al}_{5} \mathrm{FeSi}\right)$. It is clear that this phase dominates for both 6060 and 6005 alloys in the top layer of smooth surfaces.

\section{Wavy Defect Samples}

When the wavy defect surfaces (Figs. 1b, 2c and d) are formed, the meniscus is moving due to periodic variations in the metal head pressure. The length of the waves is $3-4 \mathrm{~mm}$, which corresponds to about $2 \mathrm{~s}$ at normal casting speed and can be

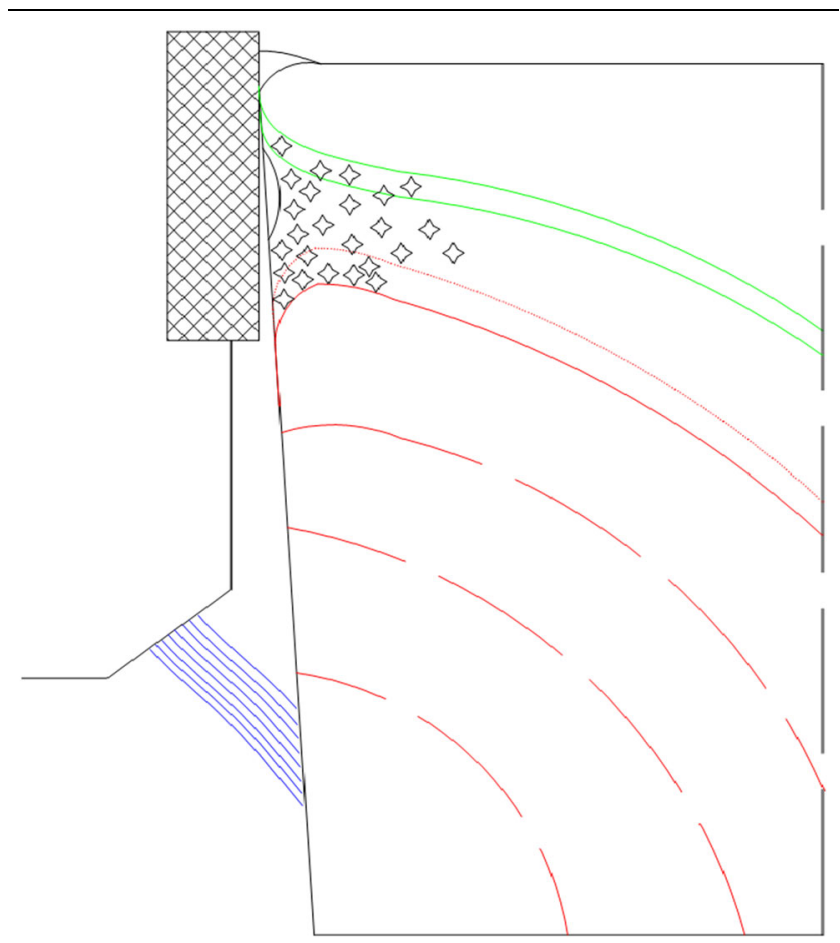

Fig. 7. Schematic drawing of billet solidification during DC casting. coupled to the frequency of the "rocking" of the liquid in the casting table. "Rocking" is an effect of bubbling when the gas, pressed through the graphite ring, is escaped through the liquid in the mold top.

When a clear wavy surface or "lapping" occurs on the surface, a "meniscus line" effect can be observed in the structure (Fig. 2c and d). When the pressure of the melt decreases, the meniscus is moving downward, and the crystals in the mushy zone are compressed against the coherent solid by the oxidecovered surface (as is shown in Fig. 8a). Therefore, the meniscus line will be a nearly linear grain boundary line contrasting to all other grain boundaries, which are randomly connected (Fig. 2c and d). Along the line, there might also be some increased amount of solute pressed out as the crystals are moved together. The lower part of the meniscus line near the surface may solidify without any exudated layer and thus with minimum surface segregation (Fig. 2c).

When the metal pressure increases again, the meniscus is lifted and new liquid moves into the space between the meniscus line and meniscus itself (Fig. 8b). This melt may already contain some floating crystals and equiaxed solidification begins. The increased pressure will make the surface, with its oxide layer, bulge out, and thus the wavy surface with the typical lapping lines is formed. The solidification of these zones can proceed in different ways, either as equiaxed growth followed by outward solidification, or if the surfaces at the bulged tips contact the graphite ring, the outward solidification might not occur. The zones will be segregation zones with higher solute content, and the thicknesses of these zones are clearly larger for the wavy surfaces than for smooth surfaces. In Ref. 13, where concentration profiles at different surfaces were measured, clear variations could be revealed. The aforementioned different solidification possibilities (a)

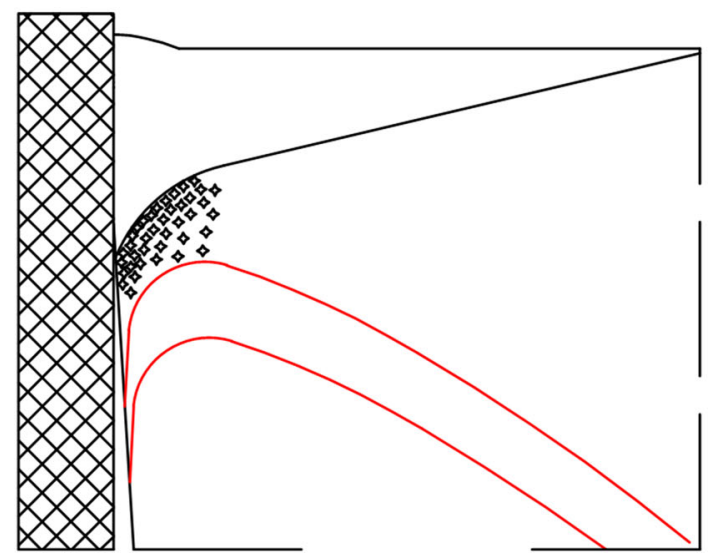

(b)

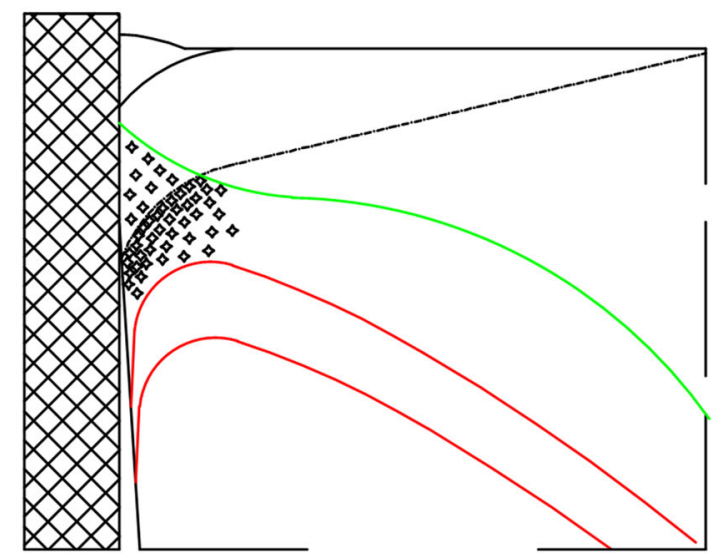

Fig. 8. Schematic model of meniscus line formation during DC casting: (a) floating crystals are pressed by meniscus and (b) meniscus line has formed after pressure reduction. 
of the segregation layer can explain the found variations, and the most important factors for the thickness of the segregated layer are the (I) alloy content and (II) metal head pressure and amplitude of the pressure variations. The casting temperature is, as long as freezing of the meniscus is avoided, of smaller importance for the surface segregation, and no differences could be revealed in this study of temperature effects.

Another factor that can influence the exudation and cause non-uniformity at the surface is cracking of the oxide layer, which allows fresh metal to come outside of the oxide layer. The melt may then fill the gap between billet and graphite ring and form another type of surface. This was, to some extent, discussed in Refs. ${ }^{6}$ and ${ }^{11}$ but appears more readily in higher alloyed billets than those discussed in this article. This phenomena has also been correlated to the surface tension and the plasticity of the meniscus, and some alloy elements can reduce the surface tension and thus the strength of the meniscus. ${ }^{12}$

The surface phases studied by SEM on the wavy surfaces are somewhat different from what was found on the smooth surface. On the latter, the plate-like beta phase was completely dominating, but on the wavy surfaces, beta phase still exists but together with other phases (Fig. 4).

Figure 4a shows a lower magnification view of the top of a wave, showing from corner to corner. In the upper-right corner, the beta phase is dominating, but on the diagonal on the top of the wave, the structure is different. Two structure features can be regularly seen, namely dendritic-like phases, which seem to have grown independently from the cellular underlying structure and are very thin. They seem to have been growing in a two-dimensional pattern on the very surface (Fig. $4 \mathrm{~b}$ and d). A phase of another morphology is filling the areas around the cells (Fig. 4e). Furthermore, a larger tip sticking out of the surface can be observed (Fig. 4c). The EDX analysis reveals $\mathrm{Fe}: \mathrm{Si}$ ratios (recalculated to at.\%) for the dendritic phases in Fig. $4 \mathrm{~d}$ of about 2:1, indicating that these phases are $\alpha$-phase with a possible composition of $\mathrm{Al}_{8} \mathrm{Fe}_{2} \mathrm{Si}^{27}{ }^{27}$ while the phase in Fig. 4e is closer to beta with a ratio of 1:1.

The different phases that appear can be understood by the fact that Fe has a small distribution coefficient, and if solute from the latest stages of the solidification are pressed into some regions, the Fe:Si ratio will be high and the alpha phase will be formed. Also, the difference between the two alloys is important, as the Si content in 6005 is higher at the start and the Fe:Si ratio will be kept lower, also after segregation, which will promote beta phase formation. It could also be seen in the cell boundaries (Fig. 4e) that more beta phase occured in the 6005 alloy. This is in agreement with what was found in transverse cuts close to the surface, ${ }^{11}$ in that phases occuring in cell boundaries in 6005 are beta phase.

\section{Spot Defect Samples}

At the spot defects, the oxide skin seems to be pinned to the solid, and the exudated layer is not able to form a continuous liquid layer at the spots (Figs. 1c, 2e and f). Especially in Fig. 1c, it looks as though there is a pressure on the oxide skin from the exudation liquid, while the pinning seems to resist the pressure. These types of spot defects often appearing along lines parallel to the billet growth direction, so-called "snail trails," and it is commonly regarded as oxide defects. In Ref. ${ }^{28}$ it was shown that it is possible to provoke these defects by introducing disturbances on the top plate (transition plate). When the liquid flow along the top plate was disturbed, lines of spot defects occurred on the billet surface.

In the EDX spectra in Fig. 5, it is clear that the elements $\mathrm{F}$ and $\mathrm{Na}$ are present at high concentrations around these spots, indicating that they may play an important role in the spot defect occurrence. $\mathrm{F}$ and $\mathrm{Na}$ are elements that can be found in cryolite $\left(\mathrm{Na}_{3} \mathrm{AlF}_{6}\right)$, which is the base for the electrolytic bath in primary aluminum production. ${ }^{29,30}$ It has often been speculated what effects the bath rests, following the aluminum to the cast house, can have on the casting. Here, it can be seen as clear evidence that $F$ and $\mathrm{Na}$ are involved in spot defect formation.

The mechanism of spot defect formation might be that disturbances of the flow will make the liquid, with its oxide skin, contact the graphite ring intermittently. Furthermore, during contact, cooling increases and solid nucleates come in contact with the oxide skin. Later, this solid nucleus will be part of the coherent crystals forming the start of the shell, but as liquid is exudated to the surface layer, the solid at these spots is connected to the skin and only the skin around the spots is bulged out.

The roll of the $\mathrm{F}$ and $\mathrm{Na}$ can be that they weaken the oxide and thus improve the contact between liquid aluminum and the graphite ring. Maybe the spot defects can also form without bath rests in the melt, as they are rather frequently occurring, but the existence of these elements probably makes the casting more sensitive to disturbances along the top plate.

\section{CONCLUSION}

Exudation of melt from the mushy zone during billet air-slip casting occurs against a flexible oxide skin, thus forming a surface layer, which solidifies outward.

The outward solidification is cellular, with more elongated cells for the 6060 alloy and more rounded for 6005 . The cellular growth gives a strong segregation to the outermost layer at the oxide skin with concentrations 5-6 times higher than bulk level.

When the meniscus is not fluctuating, because of small pressure variations in the table, a smooth billet surface is obtained, but still exudation to a layer of constant thickness occurs. 
When the meniscus is fluctuating, because of moderate pressure variations in the table, the exudation layer thickness becomes periodic and larger than at a smooth surface, but for 6060 and 6005 alloys, the layer normally stays within the oxide skin.

At smooth surfaces, the outermost layer is dominated by $\beta$-phase, while at the wavy surfaces also $\alpha$-phase at different morphologies appears.

The fluctuating meniscus with its oxide skin compresses the floating crystals against the coherency zone, thus forming the meniscus line effect.

Impurities such as $\mathrm{NaF}$ and $\mathrm{KF}$ affect the surface tensions of involved phases and cause the oxide skin to pin the solid shell, which lead to spot defects on the billet surface.

\section{ACKNOWLEDGEMENTS}

The European Development Fund is acknowledged for financial support, and Kubikenborg Aluminium $\mathrm{AB}$ is acknowledged for providing materials and for stimulating discussions of casting practices.

\section{REFERENCES}

1. W. Schneider, Light Metals 2002, ed. W. Schneider (Warrendale, PA: TMS, 2002), pp. 433-437.

2. D.G. Eskin, V.I. Savran, and L. Katgerman, Metall. Mater. Trans. A 36A, 1965 (2005).

3. J.W. Evans and W.K. Jones, Light Metals 2002, ed. W. Schneider (Warrendale, PA: TMS, 2012), pp. 669-679.

4. W.J. Bergmann, Metall. Trans. 1, 3361 (1970).

5. F. Iverson (Ph.D. Dissertation, NTNU, Trondheim, 2002).

6. D. Mortensen, B.R. Henriksen, M. Hamdi, and H.G. Fjaer, Light Metals 2008, ed. D.H. DeYoung (Warrendale, PA: TMS, 2008), pp. 773-779.

7. A.V. Reddy and C. Beckermann, Metall. Mater. Trans. B 28B, 479 (1997).

8. W.R. Osorio, J.E. Spinelli, I.L. Ferreira, and A. Garcia, Electrochim. Acta 52, 3256 (2007).

9. A.P. Boeira, I.L. Ferreira, and A. Garcia, Mater. Sci. Eng. A 435,150 (2006).
10. J.G. McGubbin, Light Metals 1975, ed. R. Rentsch (Warrendale, PA: TMS, 1975), pp. 137-159.

11. S. Benum, A. Håkonsen, J.E. Hafsås, and J. Sivertsen, Light Metals 1999, ed. C.E. Eckert (Warrendale, PA: TMS, 1999), pp. 737-742.

12. I.F. Bainbridge, J.A. Taylor, and A.K. Dahle, Light Metals 2004, ed. A.T. Tabereaux (Warrendale, PA: TMS, 2004), pp. 693-698.

13. M. Erdegren and T. Carlberg, Light Metals 2011, ed. S.J. Lindsay (Warrendale, PA: TMS, 2011), pp. 675-680.

14. H. Fredriksson and U. Åkerlind, Materials Processing During Casting, 1st ed. (Chichester, UK: Wiley, 2006), p. 148.

15. J.M. Ekenes, Light Metals 1991, ed. E. Rooy (Warrendale, PA: TMS, 1991), pp. 933-939.

16. J.F. Grandfield and P.T. McGlade, Mater. Forum 20, 29 (1996).

17. R. Nadella, D.G. Eskin, Q. Du, and L. Katgerman, Prog. Mater Sci. 53, 421 (2008).

18. M. Hamdi, A. Mo, D. Mortensen, and H.G. Fjaer, Light Metals 2002, ed. W. Schneider (Warrendale, PA: TMS, 2002), pp. 695-702.

19. W.A. Tiller, K.A. Jackson, J.W. Rutter, and B. Chalmers, Acta Metall. 1, 383 (1953).

20. Y. Du, Y.A. Chang, B. Huang, W. Gong, Z. Jin, H. Xu, Z. Yuan, Y. Lio, Y. He, and F.Y. Xie, Mater. Sci. Eng. A 363, 140 (2003).

21. M. Hamdi and A. Mo, Light Metals 2008, ed. D.H. DeYoung (Warrendale, PA: TMS, 2008), pp. 765-771.

22. H.J. Thevik, A. Mo, and T. Rusten, Metall. Mater. Trans. B 30B, 135 (1999).

23. M. Zaloznik and B. Sarler, Mater. Sci. Eng. A 413-414, 85 (2005).

24. Q. Du, D.G. Eskin, and L. Katgerman, Metall. Mater. Trans. A 38A, 180 (2007).

25. C. Beckermann, Int. Mater. Rev. 47, 243 (2002).

26. A. Prasad and I. Bainbridge, Metall. Mater. Trans. A 44A, 3099 (2013).

27. N.C.W. Kuijpers, F.J. Vermolen, C. Vuik, and S.V. Zwaag, Mater. Forum 28, 1040 (2004).

28. T. Carlberg and A.E.W. Jarfors, Metall. Mater. Trans. B 45B, 175 (2014).

29. A. Silny and T.A. Utigard, Light Metals 1997, ed. R. Huglen (Warrendale, PA: TMS, 1997), pp. 871-878.

30. C. Dupuis and J.P. Martin, Light Metals 1997, ed. R. Huglen (Warrendale, PA: TMS, 1997), pp. 857-864. 